\title{
Brief Analysis on Innovative Education as well as Assessment and Appraisal Mechanism of Chinese Universities
}

\author{
Wang Xiaobin \\ School of Economy and Management \\ Shenyang Aerospace University \\ Shenyang City, China
}

\begin{abstract}
Innovation is the soul for the progress and development of a nation and the cultivation of innovative ability shall be dominant in any industry. Under the background of quality education, the primary task of education industry is to improve students' innovative ability so as to implement the strategic deployment to build an innovation-oriented country and university students are in a key period of receiving higher education. They are granted with more opportunities to learn more and more time to research and discuss about the knowledge. By understanding and experimental research, new ideas occur to students and they may overthrow the old theory so as to innovate the education. Examination and its system are important approaches to assess and value students. However, for most of the university schools, they lack a scientific assessment system. The currently running assessment system severely hampers the implementation of innovative education. In order to guarantee the quality of innovative talents, universities have to continuously innovate and reform the assessment system. This paper studies the importance of innovative education as well as the current condition of university assessment and appraisal system so as to put forward the existing problems.
\end{abstract}

Keywords-University Education; Innovation; Assessment and Appraisal Mechanism; Reform

\section{INTRODUCTION}

Chinese socialism asks the nation to develop the innovative ability and build an innovation-oriented country. Education plays an important role in a nation and traditional education pays attention to the accumulating and understanding of knowledge. Today, in 21st century, there is a dazzling array of versatile talents yet few of them have the innovative ability. Higher education is the key point to cultivate students' innovative ability, which undertakes the historical mission to cultivate talents. The requirement of higher education is to cultivate higher talents with innovative spirit and ability. How to better arouse the creative thought of students, cultivate the innovative ability and practical ability are important projects various universities and the education field should try unremitting efforts to study. Therefore, it is necessary to strengthen quality education, arouse their creative ability, encourage innovation and fully improve students' quality and ability.

\section{THE IMPORTANCE OF INNOVATIVE EDUCATION}

In the diverse knowledge economy era, innovation is the main stream of the times, which asks to cultivate innovative talents with innovation consciousness and thought. Innovation education is a new education philosophy put forward in the new time, which abandons absolute powerful education idea comparing to traditional education methods and its essential requirement is to doubt and challenge power.

Innovative education can stimulate students' creative nature and grant them with modern scientific cultural knowledge to ignite their potential and creative ability. Innovative education has three characteristics: pioneering, that is to say teachers teach students basic knowledge and then students can have improvements by grasping the wisdom of ancestors to put forward their theoretical ideas; reactivity, which pays more attention to the social orientation comparing to traditional education; difference, that is to say everyone is an independent individual with their unique ideas, which should be respected and protected.

Innovative talents are the most valuable resources of a nation and universities are important places for talents cultivation. To cultivate innovative talents are severe challenges of the economic time as well as the objective requirement of the social development, which is also the necessity for universities to survive and develop.

\section{BRIEF ANALYSIS ON INNOVATIVE EDUCATION}

\section{A. Existing problems}

Innovative education aims to cultivate innovative talents so as to realize the comprehensive development of human beings, which is an important part of quality education as well as an important approach to implement the strategy of invigorating the country through science. In recent years, most of the universities in China deeply explore the innovative education, yet with problems. There are various and complicated factors that restrict the development and in the following we shall analyze from four aspects:

1) Old concept and insufficient cognition

Traditional educational philosophies are deeply ingrained in China, which are sacred and indubitable, stick 
to inherit the wisdom of our ancestors, indicating that the knowledge is passed down for hundreds of years and are proved by science. However, with the development of times, traditional theories cannot be adapted to the development of modern society. At the same time, the development of technology can find out theoretical loopholes which cannot be found out before. Therefore, to begin with, the first step is to come up with questions. Yet, the traditional education philosophy severely hampers the development of innovation. The traditional education only sticks to the teaching model of cramming, which is not beneficial to arouse the innovation consciousness of students.

\section{2) Obsolete content, single approach}

Innovative education aims to scientifically collect the knowledge system and create a totally new course curriculum. However, most of universities lack real practice. We are now in the information era, and the massive amounts of information asks us to have strong ability in terms of collecting and taking advantage of information which is always a weakness for most of universities. What's more, the teaching content and course setting have been outdated, which cannot meet the requirement of modern society. Staid teaching content, obsolete course setting and irrational structure cannot ignite the innovation without fresh ideas.

Innovative education firstly focuses on new things, and the teaching method should be innovative. What's more, the teachers should pay more attention to the thought of students as well as their practical ability. However, currently, most of the schools are seriously affected by exam-oriented education. In addition, the staid teaching method cannot stimulate students' interest and innovative education cannot be implemented without a good learning atmosphere.

Practice is the sole criterion for testing truth, and practical education aims to supplement and strengthen theoretical education, which is also the requirement of innovative education. However, most universities lack the capital to realize it and students cannot be granted with the opportunity to practice. For innovative education, both theory and practice are indispensable. However, the ignorance of practical education objectively hinders the development and progress of innovative education, which finally leads to the condition that students lack innovative ability and cannot meet the demand of the society.

\section{3) Impediment of traditional teaching evaluation}

With the advancement of quality education, traditional assessment and appraisal system can no longer adapt with the innovative education. At present, most universities still stick to examination-oriented education. Even though, the grades can to some extent evaluate the learning result, it is not scientific to evaluate the comprehensive quality of students only through grades. Therefore, the teaching mode as well as the education philosophy must be changed.

\section{4) Lack scientific teaching management system}

$$
\text { and policy support }
$$

Traditional teaching management system overemphasizes regularization and unification, which lacks flexibility and adaptability and cannot cultivate students' innovative ability. The current teaching management, plan, examinations management and appraisal system cannot provide powerful support for innovative work.

The work of innovative education is heavy. Therefore, it is not enough to only depend on school and students, the government should provide necessary support in terms of policies. However, the innovative education is dispensable among students and teachers even various universities encourage and promote it. Besides, there are not relevant incentive mechanisms which cannot drive them to implement the innovative education. Finally, the innovative education is superficial which comes out to be formality.

\section{B. Solutions}

\section{1) Innovate education concept}

Innovative education advocate individuation, that is to say the innovative consciousness should be established and the importance of innovation should be fully understood. Both students and teachers should establish democratic, open and changeable education philosophy so as to build correct knowledge and talent view. To begin with, the philosophy should be updated so as to cultivate talents and strengthen national innovative ability, which is closely related to the up and down of a nation and can provide a powerful guarantee for education reform. Besides, innovative idea can inspire new expectation and decision makers should lead a correct direction so as to guarantee the sound development of a healthy education system.

\section{2) Innovate cultivation model}

Cultivation model innovation aims to adopt talent cultivation model so as to make people think and carefully discuss, which can change the traditional teaching method and arouse the interest of students and save them from the dull classes. What's more, with the reform of educational system, the focus of education has been changed and traditional teaching method cannot meet the requirement of current classroom teaching. Therefore, we should try the utmost to bring the enthusiasm of students into play and lead them to think after class and explore problems. Moreover, they should be encouraged to analyze problems from different perspectives.

In addition, students should be independent to explore with innovative consciousness. The contents taught by teachers are not always right and students should be doubtful to seek the truth. While facing problems, they should put forward questions so as to solve problems together. Besides, parents should change their old fashioned ideas abandon the criteria that the grades can determine everything. Besides, students can deeply learn what they are fond of. Furthermore, while giving classes, teachers should pay attention to quality rather than quantity and ensure that the contents taught can be fully understood by students. In addition, teachers should take advantage of interesting language so as to vividly demonstrate abstract ideas so as to enliven the class.

\section{3) Innovate teaching method}

Innovating the teaching method can be deemed as an important approach and is an inevitable choice of the times. Traditional teaching model cannot adapt with the 
development of modern universities and it is urgent to promote a totally new teaching method. At the same time, the media can be adopted to vividly demonstrate the meaning and help students to learn and understand. The last but not the least, it is also urgent to establish a laboratory because theory without practice is empty and practice is the beginning to create thinking ability.

\section{CURRENT EXAMINATION AND ASSESSMENT}

\section{SYSTEM}

At present, the assessment methods in universities are examinations. Under the impulse of quality education, the assessment and appraisal system have been transited to regulated and scientific form. Yet the traditional ideas are deeply ingrained, which have powerful effect on the reform of assessment and appraisal mechanism.

\section{A. Existing problems}

\section{1) Lack of recognition of examination purpose with unreasonable contents}

Examination for students is a kind of routine work in teaching, which is adopted to summarize and evaluate the teaching of a term. However, most schools take this as the purpose of education and the mastering of a course is evaluated based on the grades. Good grades can be seemed as the accomplishment of teaching. For some science and engineering schools, such methods are defective. The grades cannot be beckoned as the purpose because it is inevitably pathetic for university students to only regard the graduate \& degree certificates as the purpose, which is also a waste of talent resources for a nation.

Concerning the examination contents, teachers give the range and highlight key contents. As a result, students remember these contents so as to deal with the exam and the purpose of innovative education has collapsed. Based on this, the true ability of students cannot be evaluated which shall lead to serious misleading.

\section{2) Unreasonable evaluation system}

Examinations, on the one hand, aim to test how students grasp the knowledge and one the other hand can be deemed as a standard to evaluate the teaching quality. However, at present, the grades are only paid attention to and no one carefully analyzes the result and find out the problems. Besides, the grades determine the learning quality and the evaluation on students. In addition, the various applications of honors are related to grades. However, the truth is that the grades can only reflect one perspective cannot evaluate students in a general sense.

\section{B. Solutions}

\section{1) Correctly understand the examination purpose and improve the paper quality}

The examination purpose should be judged by the managers, teachers and students. Examination should be only used to test the learning result of a certain period of time which aims to find out problems and make up for loopholes. By examination, we can test and supervise the teaching task and thereby to improve the education quality by mutual efforts. In addition, the assessment group is necessary to timely feedback to in order to gradually improve the learning and innovative ability.

In order to assess the comprehensive quality of students, the quality and openness of papers should be guaranteed with more subjective topics, which can ignite students' divergent thinking ability. What's more, various solutions methods are advocated so as to help student think from various perspectives. Besides, the topics in the paper should be around the teaching material, which yet cannot be confined to teaching material so as to evaluate students' ability.

\section{2) Rich the examination forms and perfect the \\ assessment system}

Modern teaching should rich the examination forms so as to cultivate technical talents as well as innovative talents. Besides, in terms of different courses, different examination forms should be adopted. For example, concerning written and spoken English, as well as practical operation, different examination exams should be adopted so as to help students exercise their ability from various aspects to comprehensively improve their quality. Besides, the assessment and appraisal mechanism should be deeply strengthened with classification tests and system so as to implement a comprehensive system. Based on this, the examination reform is pushed so as to push the reform of education, establish a scientific and reasonable evaluation and appraisal mechanism to encourage students' creativity and enthusiasm. Finally, the innovative education and assessment system is properly combined, which can accelerate the development of education industry.

\section{CONCLUSION}

In 21 st century, innovation is the mainstream of times and the development of a nation cannot be inseparable from innovation and the progress of a nation needs the contribution of innovative talents. Students are the future of a nation and education is a big issue, which should be put in a primary position. Higher education is an important sector to cultivate their innovative ability, which should be highlighted. However, innovation cannot be down at once, which should be gradually explored.

\section{REFERENCES}

[1]Li Caijun. A new probe into the innovative ability cultivation of university students $[\mathrm{M}]$. Chognqing: Chongqing Publishing House, 2006.

[2]Zhao Qingmin. Training Innovation Ability [M]. Wuhan: Huazhong University of Science and Technology Press, 2002.

[3]Li Shihai, Gao Zhaohong, Zhang Xiaoxuan. New Research on Innovative Education [M]. Beijing: Social Sciences Academic Press, 2005.

[4]Zhao Jiaji. Outline of Creative Education[M]. Chengdu : Sichuan Education Press, 2005.

[5] Liu Jijiang. Some Thoughts on the Examination Reform of University [J]. China Higher Education Research, 2000, 5: 28-29.

[6] Sun Shijie, Zhang Guorong, Feng Xiying. Research on Present Situation of University Students' Academic Achievement Evaluation and Reform $[\mathrm{J}]$ Journal of Henan Normal University : Philosophy and Social Sciences Edition, 2000, 5: 106-109.

[7]Hu Huimin. Research on the Course Examination Management of University in China[D] Central China Normal University, 2007. 
[8]Wang Zhou. Research on the Formative Assessment of Common Universities [D]. East China Normal University, 2007.

[9] Tu Yeman, Zhang Qingii. Research Summary on the Curriculum Test Reform of Applied Undergraduate College [J]. Journal of Dongguan University of Technology, 2013, 8: 107.
[10]Ma Huiliang. Applied Talents cultivation and Reform of College Examination[J]. Modern Enterprise Education, 2014, 4: 54.

[11]Li Qiaolin, Zhou Wenshan, Ye Shaocan. Research of Scientific Orientation of Modern University[J]. Journal of Hefei University of Technology(Natural Science), ,2006,(5):68-73. 